\title{
Дискуссионные статьи
}

УДК 159.923.44

ББК Ю984

DOI: $10.14529 / p s y 190109$

\section{КОНЦЕПЦИЯ ДИНАМИЧЕСКОГО ПСИХОБИОЛОГИЧЕСКОГО ГОМЕОСТАЗА И ПОЛИМОРФИЗМ СТРЕССОУСТОЙЧИВОСТИ КАК НОВЫЙ ВЗГЛЯД В ПСИХОЛОГИИ СТРЕССА}

\author{
В.Э. Цейликман, В.А. Глухова \\ Южно-Уральский государственный университет, г. Челябинск, Россия
}

\begin{abstract}
Представлены результаты теоретического аспекта изучения стрессоустойчивости, выполненного на основании анализа современных представлений зарубежной психологии. Целью исследования являлась идентификация современных перспективных подходов к изучению стрессоустойчивости для организации дальнейших междисциплинарных воздействий. Представлены характеристики двух типов стрессоустойчивости - «инженерной» и «экологической». При этом «инженерная стрессоустойчивость» рассматривается как связанная с восстановлением после пережитого стресса исходного состояния организма. «Экологическая стрессоустойчивость» характеризуется переходом организма в альтернативное состояние. Учет существования двух этих выделяемых форм стрессоустойчивости открывает новые перспективы в исследованиях психологии стресса.

Ключевые слова: стрессоустойчивость, биопсихологический гомеостаз, «инженерная стрессоустойчивость», «экологическая стрессоустойчивость».
\end{abstract}

На примере анализа состояния лиц, переживших психологические травмы, стало очевидно, что как сиюминутные, так и отдаленные их последствия воздействия различны у разных людей. Наряду с лицами, подверженными психотравмирующим воздействиям, выделяются и устойчивые к психотравмирующим воздействиям люди. Однако природа устойчивости к психологическим стрессорным воздействиям до сих пор до конца не изучена. В самых общих чертах следует считать наиболее приемлемой точку зрения о том, что «устойчивость к экстремальным ситуациям подразумевает или низкий уровень реагирования, или высокий уровень восстановления биопсихологических ресурсов» (Fletcher and Sarkar, 2013; Robertson et al., 2015).

В западной психологии идея необходимости рассмотрения феномена устойчивости к стрессу возникла в 1970-х годах при изучении детей, способных к нормальному развитию несмотря на наличие проблем и трудностей при их воспитании (Masten, 2001). К началу 1990-х годов основной фокус исследований стрессоустойчивости сместился от определения защитных факторов, которые позволяют сохранять присутствие положительных эмо- ций и способность к саморегуляции, к изучению психосоциальных детерминант резистентности к травматическим заболеваниям (Luthar et al., 2003; Conger \& Conger, 2002; Bonanno et al., 2004; Cai et al., 2017).

\section{Поведенческие характеристики} устойчивости к стрессу

Несколькими группами зарубежных исследователей, независимо друг от друга, был выявлен ряд психосоциальных факторов, способствующих формированию устойчивости к стрессу. Среди них наиболее существенными были: активное копирование (Snow-Turek et al., 1996; Hanton et al., 2013), когнитивная переоценка (Maren, 2008; Farchi and Gidron, 2010; Troy et al., 2010), просоциальное поведение (Staub and Vollhardt, 2008), социальная поддержка и другие (Ozbay et al., 2008; Cai et al., 2017). Например, социальная поддержка является одним из основных защитных элементов, который влияет на благосостояние семьи, качество воспитания и устойчивость детей к стрессу. Десятилетнее лонгитюдное исследование показало, что социальная поддержка со стороны партнеров способствовала стрессоустойчивости в ответ на экономиче- 
ский стресс (Conger \& Conger, 2002). Напротив, плохая социальная поддержка усиливала стресс, что приводило к повышению частоты сердечных сокращений (Stansfeld et al., 1997), депрессии (Oxman and Hull, 2001) и повышенной восприимчивости к посттравматическим стрессовым расстройствам (ПТСР) и др. (Johnson et al., 2014).

Несмотря на то, что наступление психических расстройств, в частности ПТСР и депрессия, может быть предотвращено путем адаптации к стрессу, ключ к устойчивости и умственному благополучию лежит в процессах регулирования эмоций (Hu et al., 2014). В более ранних исследованиях были рассмотрены варианты стратегий для построения активных путей стрессоустойчивости. При этом Garmezy et al. (1984) изучали зависимость последствий стресса от действия психотравмирующего фактора, в то время как представлялось целесообразным сфокусировать внимание на исследовании психологических ресурсов переживания стресса. Эти ранние теории оказали большое влияние на современные подходы к изучению стрессоустойчивости.

\section{Динамическая структура}

\section{стрессоустойчивости}

В последнее время большое внимание привлекает концепция «динамического биопсихологического гомеостаза», в которой стрессоустойчивость рассматривается как динамическое равновесное состояние, в котором физические, психологические и духовные компоненты, а также различные неблагоприятные или защитные факторы находятся в фазе динамического баланса. В этом контексте на стрессоустойчивость в дополнение к индивидуальным особенностям личности (невротизм, гипертимия, экстравертность, обладание чувством юмора) влияют и некоторые другие факторы - социальная поддержка, воспоминания о проблемах детства и т. д. Сложное сочетание вышеперечисленных факторов определяет то, насколько быстро люди восстанавливаются после стрессовых событий повседневной жизни (Bonanno 2004; Bonanno and Mancini 2008). Индивидуальные особенности проявляются в том, что некоторые люди способны сопротивляться стрессовым событиям, не теряя при этом самоконтроля, а другим нужно некоторое время для восстановления исходного состояния. Неустойчивые (стресс-восприимчивые) люди испытывают постоянные страдания от воздействия даже относительно слабых стрессорных событий. Стрессорная устойчивость часто рассматривается в проекции однонаправленного континуума, в котором стрессорная уязвимость считается «нулевой точкой отсчета». Лица с низкой стрессорной восприимчивостью имеют высокую устойчивость к психотравмирующей ситуации, хотя и у них имеются свои пределы выносливости (Goldberg, 1972). Такая устойчивость может быть связана с осознанием различных вариантов выигрышного реагирования в условиях стресса (Campbell \& Campbell, 2011). Из этого следует, что с точки зрения психологии и психопатологии стрессоустойчивость подразумевает способность человека адаптироваться, не позволяя при этом негативному опыту переживаний стресса доминировать в сознании, а также способность быстро восстанавливать самообладание и самочувствие. Иными словами, преодоление стресса, адаптация и восстановление психологической стабильности тесно связаны с биопсихологической устойчивостью. Однако в ряде случаев переживание психотравматических событий не прекращается даже спустя длительное время после их завершения. В тех случаях, когда полное выздоровление человека не достигается, лечение фокусируется на смягчении симптомов психического заболевания, прежде всего - с помощью медикаментов и психотерапии (последняя чаще всего направлена на развитие навыков адаптации и преодоления трудностей).

В рамках концепции «динамического биопсихологического гомеостаза» выделяют два вида «стрессоустойчивости».

Первый вид обозначается как «инженерная» или «механистическая» стрессоустойчивость, которая подразумевает способность возвращения человека после завершения стрессорных воздействий в исходное состояние без значительных модификаций его личностно-характерологических свойств. Соответственно, не претерпевает существенных изменений и нейробиологическая составляющая стрессоустойчивости. Для образного восприятия «инженерной» стрессоустойчивости полезно представить положение шарика в чаше. В устойчивом состоянии, когда ось чаши находится по отношению к плоскости опоры под углом в 90 градусов, шарик находится на дне чаши. При отклонениях оси чаши в ту или иную сторону (стрессорные факторы) шарик меняет свое положение относительно ранее имевшейся точки на дне и возвращается в ис- 
ходное положение после того, как чаша снова приобретет устойчивое положение. Такое представление об «инженерной стрессоустойчивости» может оказаться весьма полезным для понимания способности людей справляться с вызванными стрессом симптомами психологических расстройств и продолжать жить в привычном режиме. Для реализации «инженерной» стрессоустойчивости человек может опираться исключительно на свои психологические ресурсы и обходиться без особых перестроек нейро-иммунно-эндокринной, психофизиологической и собственно психологической регуляции. Хотя следует полагать, что лица с таким видом стрессоустойчивости существенно отличаются по нейро-биологическим, эндокринным, метаболическим, психологическим и иным показателям от других людей. Вместе с тем полезность такой формы стрессоустойчивости представляется относительной. К сожалению, весьма редко внимание исследователей фокусируется на негативных моментах, связанных со стрессоустойчивостью. Тем не менее существует точка зрения П.Б. Зильбермана (1972) о том, что стрессоустойчивость может быть нецелесообразным явлением, характеризующим отсутствие адекватного отражения изменившейся ситуации, свидетельствующим о недостаточной гибкости, приспособляемости. На наш взгляд, такое представление особенно может быть справедливым применительно к «инженерной стресс-устойчивости».

Второй вид обозначается как «экологическая стрессоустойчивость» и рассматривается как своеобразная аналогия между биопсихо логическими изменениями у лиц, подвергнутых стрессу, с одной стороны, с изменениями, происходящими в экологических системах в ходе природных катаклизмов, с другой. В отличие от «инженерной стрессоустойчивости» этот вид предполагает переход из одного состояния в другое, а не возврат в исходное состояние. При этом наблюдаются глубокие биопсихологические перестройки вплоть до «психологических ароморфозов». На уровне нейробиологии и нейро-иммунно-эндокринологии особенности «экологической стрессоустойчивости» адекватно характеризует хорошо описанное в научной литературе состояние аллостаза, который чаще всего определяется как гомеостаз, достигаемый путем напряжения механизмов нейро-эндокринной регуляции.

Таким образом, если инженерная стрессоустойчивость сфокусирована на способности возврата в исходное состояние, то экологическая стрессоустойчивость подразумевает переход от исходного состояния к альтернативному состоянию. Причем альтернативных состояний может быть неограниченное множество.

Описываемые виды стрессоустойчивости могут составлять важную в методологическом и методическом плане основу развития теоретических положений дальнейших междисциплинарных исследований проблемы стресса.

Исследование выполнено в рамках базовой части Государственного задания Министерства образования и науки РФ № $17.7255 .2017 / 8.9$.

\section{Литература/References}

1. Зильберман, П.Б. Эмоциональная устойчивость оператора. Очерки психологии труда оператора. М.: Наука, 1972. С. 138-152. [Zil'berman P.B. [Emotional Stability of the Operator]. Ocherki psikhologii truda operatora [Digest of the Psychology of Labor of the Operator]. Moscow, Nauka Publ., 1972, pp. 138-152. (in Russ.)]

2. Bonanno G.A. Loss, trauma, and human resilience: have we underestimated the human capacity to thrive after extremely aversive events? Am Psychol., 2004, vol. 59, pp. 20-28. DOI: 10.1037/0003066X.59.1.20.

3. Bonanno G.A., Mancini A.D. The human capacity to thrive in the face of potential trauma. $P e$ diatrics, 2008, vol. 121, pp. 369-375. DOI: 10.1542/peds.2007-1648.

4. Cai W.-P., Pan Y., Zhang S.-M., Wei C., Dong W., Deng G.-H.. Relationship between cognitive emotion regulation, social support, resilience and acute stress responses in Chinese soldiers: exploring multiple mediation model. Psychiatry Res., 2017, vol.256, pp. 71-78. DOI: 10.1016/j.psychres.2017.06.018.

5. Campbell J.E. Teachers and mental health: the art of accurate speech and other ways to help students (children) not become psychiatric patients. Bloomington, AuthorHouse, 2011. $112 \mathrm{p}$. 
6. Conger R.D., Conger K.J. Resilience in Midwestern families: selected findings from the first decade of a prospective, longitudinal study. J. Marriage Fam. 2002, vol. 64, pp. 361-373. DOI: 10.1111/j.1741-3737.2002.00361.x

7. Farchi M., Gidron Y. The effects of "psychological inoculation" versus ventilation on the mental resilience of Israeli citizens under continuous. J. Nerv. Ment. Dis., 2010, vol. 198, pp. 382-384. DOI: 10.1097/NMD.0b013e3181da4b67.

8. Fletcher D., Sarkar M. Psychological resilience: a review and critique of definitions, concepts, and theory. Eur. Psychol., 2013, vol. 18, pp. 12-23. DOI: 10.1027/1016-9040/a000124.

9. Garmezy N., Masten A.S., Tellegen A. The study of stress and competence in children: a building block for developmental psychopathology. Child Dev., 1984, vol. 55, pp. 97-111. DOI: $10.2307 / 1129837$.

10. Goldberg D. The detection of psychiatric illness by questionnaire: a technique for the identification and assessment of non-psychotic psychiatric illness. London, Oxford University Press, 1972.

11. Hanton S., Neil R., Evans L. Hardiness and anxiety interpretation: an investigation into coping usage and effectiveness. Eur. J. Sport Sci., 2013, vol. 13, pp. 96-104. DOI: 10.1080/17461391.2011.63581.

12. Hu T., Zhang D., Wang J., Mistry R., Ran G., Wang X. Relation between emotion regulation and mental health: a meta-analysis review. Psychol. Rep., 2014, vol. 114, pp. 341-362. DOI: 10.2466/03.20.pr0.114k22w4.

13. Johnson D.C., Thom N.J., Stanley E.A., Haase L., Simmons A.N., Shih P.A., et al. Modifying resilience mechanisms in at-risk individuals: a controlled study of mindfulness training in Marines preparing for deployment. Am.J. Psychiatry, 2014, vol. 171, pp. 844-853. DOI: 10.1176/appi.ajp.2014.13040502.

14. Luthar S.S. Resilience and vulnerability: Adaptation in the context of childhood adversities. Cambridge, Cambridge University Press, 2003. DOI: 10.1017/CBO9780511615788.

15. Maren S. Pavlovian fear conditioning as a behavioral assay for hippocampus and amygdala function: cautions and caveats. Eur. J. Neurosci., 2008, vol. 28, pp. 1661-1666. DOI: 10.1111/j.14609568.2008.06485.x

16. Masten A.S. Ordinary magic. Resilience processes in development. Am. Psychol., 2001, vol. 56, pp. 227-238. DOI: 10.1037/0003-066x.56.3.227.

17. Oxman T.E., Hull J.G. (2001). Social support and treatment response in older depressed primary care patients. J. Gerontol. B Psychol. Sci. Soc. Sci., 2001, vol. 56(1), pp. 35-45. DOI: 10.1093/geronb/56.1.P35.

18. Ozbay F., Fitterling H., Charney D., Southwick S. Social support and resilience to stress across the life span: a neurobiologic framework. Curr. Psychiatry Rep., 2008, vol. 10, pp. 304-310. DOI: 10.1007/s11920-008-0049-7.

19. Robertson I.T., Cooper C.L., Sarkar M., Curran T. Resilience training in the workplace from 2003 to 2014: a systematic review. J. Occup. Organ. Psychol., 2015, vol. 88, pp. 533-562. DOI: 10.1111 joop.12120.

20. Snow-Turek A.L., Norris M.P., Tan G. Active and passive coping strategies in chronic pain patients. Pain, 1996, vol. 64 (3), pp. 455-462. DOI: 10.1016/0304-3959(95)00190-5

21. Stansfeld S.A., Fuhrer R., Head J., Ferrie J., Shipley M. (1997). Work and psychiatric disorder in the Whitehall II Study. J. Psychosom. Res. 43, 73-81. 10.1016/s0022-3999(97)00001-9

22. Staub E., Vollhardt J. Altruism born of suffering: the roots of caring and helping after victimization and other trauma. Am. J. Orthopsychiatry, 2008, vol. 78, pp. 267-280. DOI: 10.1037/a0014223.

23. Troy A.S., Wilhelm F.H., Shallcross A.J., Mauss I.B. Seeing the silver lining: cognitive reappraisal ability moderates the relationship between stress and depressive symptoms. Emotion, 2010, vol. 10, pp. 783-795. DOI: 10.1037/a0020262.

Цейликман Вадим Эдуардович, профессор, директор Высшей медико-биологической школы, Южно-Уральский государственный университет (Челябинск), tceilikmanve@susu.ru

Глухова Вера Александровна, старший научный сотрудник НОЦ «Биомедицинские технологии», лаборатория «Психология и психофизиология стрессоустойчивости и креативности», Южно-Уральский государственный университет (Челябинск), glukhovava@susu.ru

Поступила в редакцию 11 января 2019 2. 
DOI: $10.14529 / p s y 190109$

\title{
THE CONCEPT OF DYNAMIC PSYCHOBIOLOGICAL HOMEOSTASIS AND STRESS TOLERANCE POLYMORPHISM AS A NEW LOOK IN STRESS PSYCHOLOGY
}

\author{
V.E. Tseylikman, tceilikmanve@susu.ru \\ V.A.Glukhova, glukhovava@susu.ru \\ South Ural State University, Chelyabinsk, Russian Federation
}

The article presents the results of a theoretical study of stress resistance, based on the analysis of modern ideas of foreign psychology. The aim of the study was to identify modern perspective approaches to the study of stress resistance for further interdisciplinary impacts. The characteristics of two types of stress tolerance - "engineering" and "environmental" are presented. "Engineering stress tolerance" is associated with the restoration of the initial state of the body after the experienced stress. "Environmental stress tolerance" is characterized by the transition of the body to an alternative state. Explaining the existence of two forms of stress resistance opens up new perspectives in studies of stress psychology.

Keywords: stress tolerance, biopsychological homeostasis, "engineering stress tolerance”, "environmental stress tolerance".

The study was carried out as the basic part of the State task of the Ministry of Education and Science of the Russian Federation No. 17.7255.2017/8.9

Received 11 January 2019

\section{ОБРАЗЕЦ ЦИТИРОВАНИЯ}

Цейликман, В.Э. Концепция динамического психобиологического гомеостаза и полиморфизм стрессоустойчивости как новый взгляд в психологии стресса / В.Э. Цейликман, В.А. Глухова // Вестник ЮУрГУ. Серия «Психология». - 2019. - Т. 12, № 1. - С. 92-96. DOI: $10.14529 /$ psy190109

\section{FOR CITATION}

Tseylikman V.E., Glukhova V.A. The Concept of Dynamic Psychobiological Homeostasis and Stress Tolerance Polymorphism as a New Look in Stress Psychology. Ser. Psychology. 2019, vol. 12, no. 1, pp. 92-96. (in Russ.). DOI: $10.14529 /$ psy190109 